\title{
Expression of L1 protein correlates with cluster of differentiation 24 and integrin $\beta 1$ expression in gastrointestinal stromal tumors
}

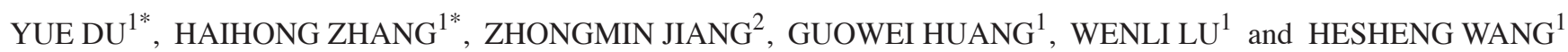 \\ ${ }^{1}$ Department of Public Health, Tianjin Medical University, Tianjin 300070; ${ }^{2}$ Department of Pathology, \\ Tianjin Fifth Central Hospital, Tianjin 300450, P.R. China
}

Received September 9, 2014; Accepted January 29, 2015

DOI: $10.3892 / 01.2015 .3096$

\begin{abstract}
The present study examined 66 cases of gastrointestinal stromal tumors (GISTs), 20 cases of smooth muscle tumors, 20 cases of schwannomas and 20 cases of normal gastric tissues in order to analyze the expression of L1, cluster of differentiation (CD) 24 and integrin $\beta 1$ by immunohistochemical staining. Patients were subjected to follow-up, and survival data were evaluated. L1 expression was detected in $57.6 \%$ of GIST cases; this was a significantly higher percentage compared with that found in the smooth muscle tumor cases or the normal control group. CD24 and integrin $\beta 1$ were also expressed at significantly higher levels in the GIST cases than in the normal control group, although no significant difference was found in the expression levels of these proteins in smooth muscle tumor or schwannoma cases. These higher levels of L1 and integrin $\beta 1$ expression were associated with an increased risk of invasive GIST, and were significantly positively correlated with Ki-67 expression. CD24 expression was not associated with the risk of GIST invasion or Ki-67 expression. There were positive correlations between L1, CD24 and integrin $\beta 1$ expression; however, these had no significant association with patient survival. Therefore, L1 alone or in conjunction with CD24 (L1 + CD24), or integrin $\beta 1$ $(\mathrm{L} 1+$ integrin $\beta 1)$ can be considered a valuable indicator for the differential diagnosis of GIST. Furthermore, L1 and integrin $\beta 1$ can be used alone or in combination to evaluate the biological behavior of GISTs. Future studies are required to evaluate the prognostic value of these markers.
\end{abstract}

Correspondence to: Professor Hesheng Wang, Department of Public Health, Tianjin Medical University, 22 Qixiangtai Road, Heping, Tianjin 300070, P.R. China

E-mail: heshengguang2014@163.com

${ }^{*}$ Contributed equally

Key words: gastrointestinal stromal tumor, L1, cluster of differentiation 24 , integrin $\beta 1$

\section{Introduction}

Gastrointestinal stromal tumors (GISTs) are the most common type of gastrointestinal mesenchymal tumor (GIMT), and can be classified as being of spindle, epithelioid or mixed cell type based on morphology (1). Recent studies have identified that a gain-of-function mutation in the c-kit gene can be found in $95 \%$ of GIST cases. This mutation facilitates ligand-independent activation of the tyrosine kinase function of KIT [also known as cluster of differentiation (CD)117] and can be used to aid the diagnosis of GISTs $(2,3)$. GISTs are commonly diagnosed on the basis of the expression levels of a range of proteins, which include CD117, CD34, smooth muscle actin (SMA), desmin and S-100 (4,5). However, a small percentage of GIST cases are negative for CD117 expression, which can complicate the diagnosis (6).

The primary treatment modality for GISTs is surgical removal, with traditional radiation and chemotherapy being ineffective (7). Furthermore, the recurrence and metastasis rate following surgical treatment is as high as $80 \%$, and the five-year survival rate is only $50 \%$ (8). Treatment with imatinib offers hope to GIST sufferers, but this also has limitations (9). Effective decision-making as to which treatment option to pursue may therefore be aided by accurate evaluation of the biological behavior of individual GIST cases.

Since its proposal, the precise definition of GIST has been controversial. Currently, it is universally acknowledged that GISTs possess malignant potential; however, the classification of the degree of this malignancy does not have a common standard (10). It is typically believed that the tumor size and mitotic activity are the most important criteria to distinguish benign from malignant tumors (11). The study by Fletcher et al provides a reasonable and detailed classification that divides GISTs into four grades, with an extremely low, low, moderate or high risk of invasion based on tumor size and mitotic activity (12). However, studies have shown that certain small tumors that are $<2 \mathrm{~cm}$ in size and without detectable mitotic activity possess an invasive capacity $(7,10,13)$. Therefore, this field remains an active research area, with current efforts focused on seeking novel molecular markers that have a higher sensitivity and specificity for the prediction of the biological behavior of tumors (14). 
CD171, also known as L1, is an adhesion molecule that regulates attachments between neighboring cells, or between cells and their surrounding extracellular matrix (ECM) through interactions with additional L1 molecules or with other ligands, such as integrin $\beta 1$ and CD24 (15). L1 is important in the development of the nervous system, and high expression levels of L1 protein have been identified in nerve-derived tumors and other solid tumors, including pancreatic cancer, ovarian cancer, melanoma, small cell lung cancer, colorectal cancer and breast cancer, where it is associated with metastasis $(16,17)$. Similar to L1, CD24 is also an adhesion molecule, and is expressed on the surface of human B cells and cells of the nervous system. Recently, high levels of CD24 have been identified on cancerous cells of the hematopoietic system and certain solid tumors. In such cases, CD24 functions as a ligand of P-selectin and has been indicated to be involved in the invasion and metastasis of tumors (18). Integrin $\beta 1$ is an important receptor for cellular adhesive molecules, and it plays a central role in the processes of tumor formation, growth, differentiation and metastasis, by mediating signal transduction and regulating adhesion between cells or between a cell and the ECM (19). The present study examined the expression levels of L1, CD24 and integrin $\beta 1$ in human GIST samples, and assessed the association between these molecules and the invasion, local recurrence and distant metastasis of cancer cells, and patient prognosis.

\section{Materials and methods}

Tissue specimens. The paraffin blocks of 106 cases of GIMT diagnosed by the Department of Pathology of the Tianjin Medical University Cancer Institute and Hospital (Tianjin, China) between January 1990 and December 2013 were collected. Based on the morphological characteristics and immunohistochemical staining of CD117, CD34, SMA, desmin and S-100 protein, 66 cases of GISTs, 20 cases of smooth muscle tumors and 20 cases of schwannomas were diagnosed. All cases were re-examined by a pathologist to confirm the initial diagnosis. Hematoxylin and eosin (HE)-stained sections from each tumor were reevaluated for the following features: Tissue type, presence of necrosis and mitotic activity (observation of 50 fields obtained at x400 magnification). This study was approved by the ethics committee of Tianjin Fifth Central Hospital (Tianjin, China) and written informed consent was obtained from all patients.

Immunohistochemical staining. The paraffin blocks were cut into sequential 5- $\mu \mathrm{m}$ sections for HE (Invitrogen Life Technologies, Carlsbad, CA, USA) and immunohistochemical (IHC) staining. Briefly, the sections were fixed with $4 \%$ paraformaldehyde at room temperature for $30 \mathrm{~min}$, and washed three times with phosphate-buffered saline (PBS; Beijing Zhongshan Golden Bridge Biotechnology Co., Ltd., Beijing, China) for $3 \mathrm{~min}$, followed by treatment with $1 \%$ Triton X-100 (Beijing Zhongshan Golden Bridge Biotechnology Co., Ltd.) and blocking with goat serum (Invitrogen Life Technologies) for $30 \mathrm{~min}$. Next, the serum was discarded and the antibody working solution [containing monoclonal mouse anti-human L1 (1:100; Thermo Fisher Scientific, Waltham, MA, USA) CD24 (1:75; Thermo Fisher Scientific), intergrin $\beta 1$ (1:150;
Santa Cruz Biotechnology, Dallas, TX, USA) and Ki-67 (1:200; Dako, Glostrup, Denmark) antibodies] was added for overnight incubation at $4{ }^{\circ} \mathrm{C}$ (Table I). Biotinylated polyclonal goat anti-mouse secondary antibody (1:200; ZDR-5307, Beijing Zhongshan Golden Bridge Biotechnology Co., Ltd.) and horseradish peroxidase-labeled streptavidin (Beijing Zhongshan Golden Bridge Biotechnology Co., Ltd.) were then sequentially added. Subsequent to coloration, the sections were stained with hematoxylin, and finally mounted with cover slips. A known positive plate, obtained from a patient with retroperitoneal schwannoma (Tianjin Medical University Cancer Institute and Hospital) was used as a positive control, and the primary antibody was replaced with PBS in the negative control.

Standards for evaluation of immunohistochemical staining. Cells with brown staining in the membrane and cytoplasm were considered L1-, CD24- and integrin $\beta 1$-positive cells. Staining results were observed and scored independently by two pathologists. A total of 10 fields at high magnification were randomly selected. The percentage of positive cells in the total number of cells in each field was scored on a scale of $0-3$, as follows: No positive cells, $0 ;<25 \%$ positive cells, 1 ; $26-50 \%$ positive cells, 2 ; and $>50 \%$ positive cells, 3 .

Evaluation of the biological behavior of GISTs. All cases were divided into groups according to the evaluation standards of the biological behavior of GISTs, as defined by Fletcher's scheme (Table II) (12). GIST samples $(n=66)$ were divided into four groups based on the standards outlined in Table II, with three cases in group I, 18 cases in group II, 19 cases in group III and 26 cases in group IV.

Patient follow-up and survival analysis. Patients were followed up by telephone, letter and a review of their clinical follow-up records, with their survival or mortality documented. The cause of mortality was determined in detail. Only patients that survived or succumbed as a result of their GISTs were selected for the statistical study of survival analysis.

Statistical analysis. SPSS statistical software, version 13.0 (SPSS, Inc., Chicago, IL, USA), was employed for the statistical analysis. Immunohistochemical results were analyzed using $\chi^{2}$ tests and Spearman's rank correlation. Kaplan-Meier survival curve analysis was employed for the follow-up data, and comparison of survival rates between groups was also performed with the log-rank test. $\mathrm{P}<0.05$ was considered to indicate a statistically significant difference.

\section{Results}

Clinical data. Tumor samples from 106 individuals were examined in this study, with 66 cases of GISTs, 20 cases of smooth muscle tumors and 20 cases of schwannomas identified. The 66 patients with GISTs included 36 males and 30 females, aged from 24-77 years, with a median age of 55 years. There were 58 cases of primary tumors, 8 cases of recurrence and 6 cases of metastasis. Tumors of low malignant potential exhibited clear borders, and were solid tumors with grey-white sections and a braided pattern. Tumors with moderate or high malig- 
Table I. First antibody dilution, pre-treatment and sources.

\begin{tabular}{lcccc}
\hline First antibody & Clone no. & Dilution & Pre-treatment & Source $^{\mathrm{a}}$ \\
\hline L1 & UJ127 & $1: 100$ & High pressure retrieval in citric acid buffer (pH 6.0) & NeoMarkers \\
CD24 & SN3b & $1: 75$ & High pressure retrieval in citric acid buffer (pH 6.0) & NeoMarkers \\
Integrin $\beta 1$ & 4B7R & $1: 150$ & & Santa Cruz \\
Ki-67 & MIB-1 & $1: 200$ & High pressure retrieval in citric acid buffer (pH 6.0) & Biotechnology, Inc. \\
\hline
\end{tabular}

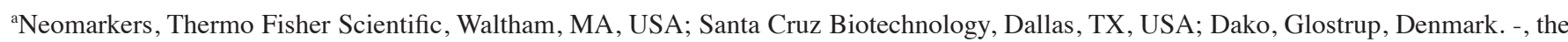
section was not treated; CD24, cluster of differentiation 24.

Table II. Fletcher's scheme for the evaluation of the biological behavior of gastrointestinal stromal tumors.

\begin{tabular}{llcr}
\hline Group & \multicolumn{1}{c}{ Category feature } & Maximum diameter, cm & Mitotic count (no./50 HPF) \\
\hline I & An extremely low risk of invasion & $<2$ & $<5$ \\
II & A low risk of invasion & $2-5$ & $<5$ \\
III & A moderate risk of invasion & $<5$ & $6-10$ \\
& & $5-10$ & $<5$ \\
IV & A high risk of invasion & $>5$ & $>5$ \\
& & Any size & $>10$ \\
\end{tabular}

HPF, high-power field.

Table III. Association between L1 expression and the clinical pathological features in gastrointestinal stromal tumor patients.

\begin{tabular}{|c|c|c|c|c|c|}
\hline \multirow[b]{2}{*}{ Items } & \multirow[b]{2}{*}{ Cases, n } & \multicolumn{2}{|c|}{ Positive expression of L1 } & \multirow[b]{2}{*}{$\chi^{2}$} & \multirow[b]{2}{*}{ P-value } \\
\hline & & Cases, n & Percentage & & \\
\hline Gender & & & & 0.405 & $>0.05$ \\
\hline Male & 36 & 22 & 61.1 & & \\
\hline Female & 30 & 16 & 53.3 & & \\
\hline Age, years & & & & 3.753 & $>0.05$ \\
\hline$<55$ & 22 & 9 & 40.9 & & \\
\hline$\geq 55$ & 44 & 29 & 65.9 & & \\
\hline Location & & & & 1.972 & $>0.05$ \\
\hline Esophagus $^{\mathrm{a}}$ & 1 & 0 & 0.0 & & \\
\hline Stomach & 27 & 15 & 55.6 & & \\
\hline Small intestine & 16 & 12 & 75.0 & & \\
\hline Large intestine & 7 & 4 & 57.1 & & \\
\hline Parenteral & 15 & 7 & 46.7 & & \\
\hline Histological type & & & & 0.020 & $>0.05$ \\
\hline Spindle cell type & 49 & 28 & 57.1 & & \\
\hline Epithelioid cell type & 5 & 3 & 60.0 & & \\
\hline Mixed cell type & 12 & 7 & 58.3 & & \\
\hline
\end{tabular}

${ }^{a}$ Results from the tumor found in the esophagus were pooled with the stomach group.

nant potential had a clearer border or false membrane, and a number displayed signs of infiltrative growth, such as invasion of the muscular layer, mucous membrane, retina, pancreas or spleen. Secondary ulceration was occasionally found on the digestive tract mucosa surface, and the tumor texture was soft and was grey-white or grey-red in colour. Bleeding, necrosis 
Table IV. Expression analysis of L1, CD24, integrin $\beta 1$ and Ki-67 in gastrointestinal stromal tumors with different invasive risks.

\begin{tabular}{|c|c|c|c|c|c|c|c|c|c|}
\hline \multirow[b]{2}{*}{ Target } & \multirow[b]{2}{*}{ Grade } & \multirow[b]{2}{*}{ Total, $\mathrm{n}$} & \multicolumn{4}{|c|}{ IHC results, $\mathrm{n}$} & \multirow[b]{2}{*}{ Positive rates, $\%$} & \multirow[b]{2}{*}{$\chi^{2}$} & \multirow[b]{2}{*}{ P-value } \\
\hline & & & - & + & ++ & +++ & & & \\
\hline \multirow[t]{4}{*}{ L1 } & I & 3 & 2 & 1 & 0 & 0 & 33.3 & 7.853 & $<0.05$ \\
\hline & II & 18 & 12 & 4 & 1 & 1 & 33.3 & & \\
\hline & III & 19 & 7 & 5 & 4 & 3 & 63.2 & & \\
\hline & IV & 26 & 7 & 6 & 7 & 6 & 73.1 & & \\
\hline \multirow[t]{4}{*}{$\mathrm{CD} 24$} & I & 3 & 2 & 1 & 0 & 0 & 33.3 & 1.841 & $>0.05$ \\
\hline & II & 18 & 6 & 7 & 4 & 1 & 66.7 & & \\
\hline & III & 19 & 4 & 6 & 7 & 2 & 78.9 & & \\
\hline & IV & 26 & 6 & 7 & 7 & 6 & 76.9 & & \\
\hline \multirow[t]{4}{*}{ Integrin $\beta 1$} & I & 3 & 2 & 1 & 0 & 0 & 33.3 & 13.088 & $<0.05$ \\
\hline & II & 18 & 10 & 5 & 2 & 1 & 44.4 & & \\
\hline & III & 19 & 6 & 5 & 5 & 3 & 68.4 & & \\
\hline & IV & 26 & 4 & 4 & 10 & 8 & 84.6 & & \\
\hline \multirow[t]{4}{*}{ Ki-67 } & I & 3 & 3 & 0 & 0 & 0 & 0.0 & 17.682 & $<0.05$ \\
\hline & II & 18 & 12 & 4 & 2 & 0 & 33.3 & & \\
\hline & III & 19 & 5 & 6 & 5 & 3 & 73.7 & & \\
\hline & IV & 26 & 4 & 5 & 8 & 9 & 84.6 & & \\
\hline
\end{tabular}

CD24, cluster of differentiation 24; IHC, immunohistochemical staining.

Table V. Correlation between the follow-up results and the expression of L1, CD24 and integrin $\beta 1$.

\begin{tabular}{|c|c|c|c|c|c|c|c|c|c|}
\hline Target & Type & $\begin{array}{l}\text { Patients } \\
\text { followed } \\
\text { up, n }\end{array}$ & $\begin{array}{l}\text { Duration of } \\
\text { follow-up, } \\
\text { months }\end{array}$ & Succumbed, n & Imatinib, $\mathrm{n}$ & Chemotherapy, $\mathrm{n}$ & Radiotherapy, n & $\chi^{2}$ & P-value \\
\hline \multirow[t]{2}{*}{ L1 } & $\mathrm{P}$ & 16 & $1-71$ & 7 & 1 & 0 & 1 & 3.26 & 0.07 \\
\hline & $\mathrm{N}$ & 11 & $4-59$ & 0 & 4 & 3 & 0 & & \\
\hline \multirow[t]{2}{*}{ CD24 } & $\mathrm{P}$ & 18 & $1-71$ & 6 & 2 & 1 & 0 & 0.69 & 0.41 \\
\hline & $\mathrm{N}$ & 9 & $8-60$ & 1 & 3 & 2 & 1 & & \\
\hline \multirow[t]{2}{*}{ Integrin $\beta 1$} & $\mathrm{P}$ & 17 & $1-71$ & 4 & 1 & 0 & 1 & 0.53 & 0.46 \\
\hline & $\mathrm{N}$ & 10 & $6-59$ & 3 & 4 & 3 & 0 & & \\
\hline
\end{tabular}

P, positive; N, negative; CD24, cluster of differentiation 24.

and cystic degeneration were commonly observed in the larger tumors.

Association between 1 protein level and the clinical pathological features of GISTs. L1 expression was identified in $57.6 \%(38 / 66)$ of the GIST cases; this was significantly higher than the percentage for the control group $(\mathrm{P}<0.05)$. However, no significant differences in L1 expression were found with regard to gender, age, tumor location or tumor histological type $(\mathrm{P}>0.05)$ (Table III).

Expression levels of L1, CD24, integrin $\beta 1$ and Ki-67 in GISTs with different invasion risks. The expression rates for L1, CD24, integrin $\beta 1$ and $\mathrm{Ki}-67$ in the GIST cases were 57.6\% (38/66), $72.7 \%$ (48/66), 66.7\% (44/66) and 63.6\% (42/66), respectively; all found elevated with an increased risk of invasion. Statistical analyses revealed significant differences in L1, integrin $\beta 1$ and $\mathrm{Ki}-67$ expression in the different invasive GIST groups $(\mathrm{P}<0.05)$, while significant difference in $\mathrm{CD} 24$ expression was found ( $\mathrm{P}>0.05$ ) (Table IV; Fig. 1).

Correlation between L1, CD24, integrin $\beta 1$ and Ki-67 protein expression level in GISTs with increasing risk of invasion. Spearman's rank correlation analysis was used to determine the existence of any association between the expression levels of L1, CD24, integrin $\beta 1$ and Ki-67 in the GIST cases. Expression levels of L1, CD24 and integrin $\beta 1$ were correlated with increasing invasiveness $(r=0.312$, $\mathrm{P}<0.05 ; \mathrm{r}=0.323, \mathrm{P}<0.05$; and $\mathrm{r}=0.298, \mathrm{P}<0.05$, respectively). $\mathrm{L} 1$ and integrin $\beta 1$ expression levels were also correlated 


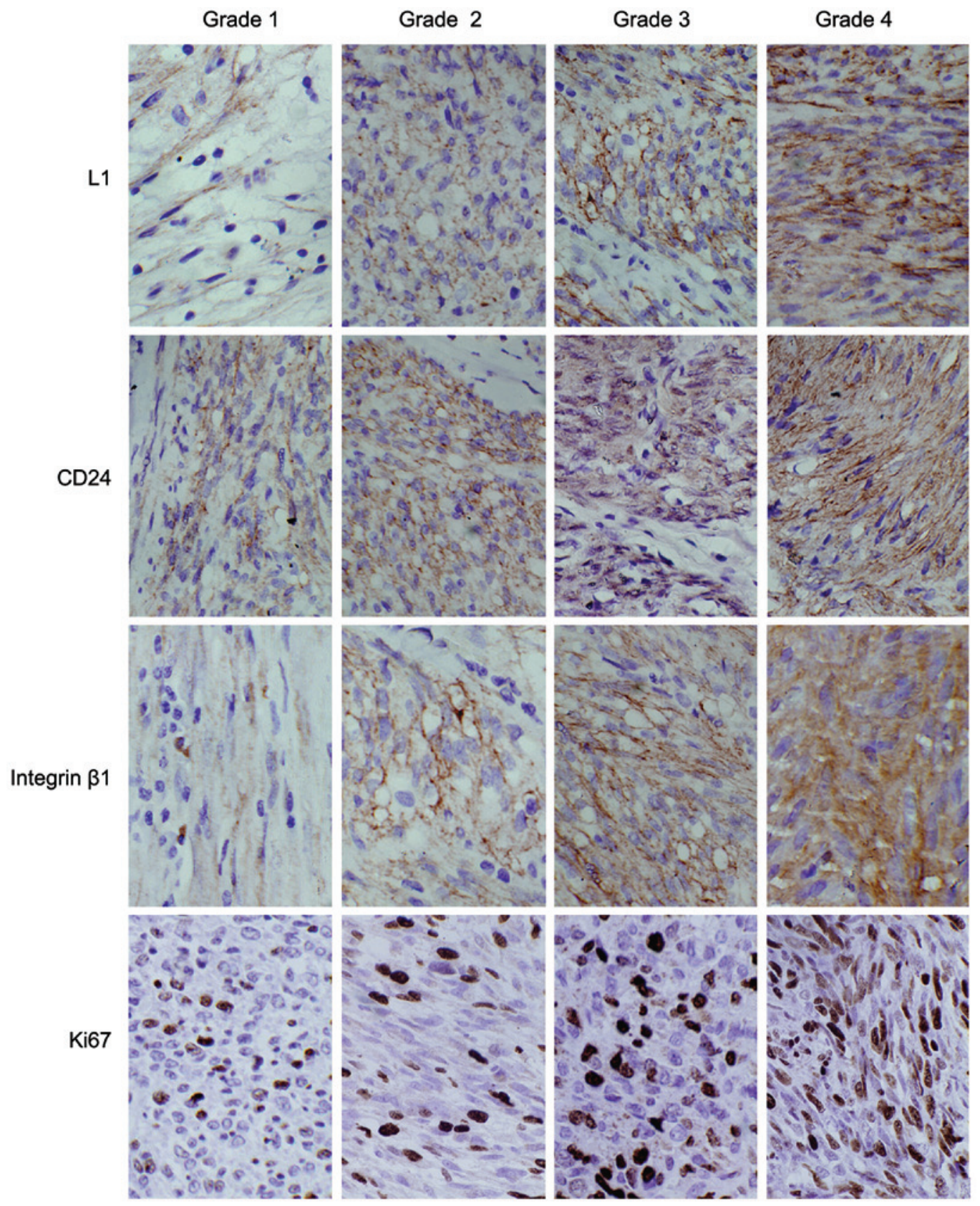

Figure 1. Analysis of L1, cluster of differentiation (CD)24, integrin $\beta 1$ and Ki-67 protein expression in gastrointestinal stromal tumors with different invasive risks. Sections were analyzed by immunohistochemistry (magnification, x200).

with the Ki-67 proliferation index $(\mathrm{r}=0.291, \mathrm{P}<0.05$; and $\mathrm{r}=0.379, \mathrm{P}<0.05$, respectively).

Expression levels of L1, CD24 and integrin $\beta 1$ in GIST, smooth muscle tumor and schwannoma samples. While positive L1 expression ws identified in 38 out of the 66 GIST cases and in 15 out of the 20 schwannoma cases, no L1 expression was observed in the 20 cases of gastrointestinal smooth muscle tumors. Statistically, there was a significant difference in L1 expression between the GISTs and smooth muscle tumors $(\mathrm{P}<0.05)$; however, no such significant difference was identified when the GIST cases were compared with the schwannoma cases $(\mathrm{P}>0.05)$. The expression levels of $\mathrm{CD} 24$ and integrin $\beta 1$ in the GIST, smooth muscle tumor and schwannoma cases were 72.7, 66.7 and $80.0 \%$, and 70.0, 100.0 and $66.7 \%$, respectively. No differences in the expression levels of CD24 or integrin $\beta 1$ were identified among the three types of tumors (P>0.05) (Fig. 2).

Follow-up results. Of the 66 patients with GISTs, 27 were followed up over 1-71 months, with an average of 24 months. No significant correlation was identified between the expression of L1, CD24 or integrin $\beta 1$ and patient survival (Table V); Kaplan-Meier survival curve analysis was also performed with an identical conclusion (Fig. 3).

\section{Discussion}

In 1983, Mazur and Clark discovered that the gastric stromal tumors once diagnosed as leiomyoma (smooth muscle tumors 


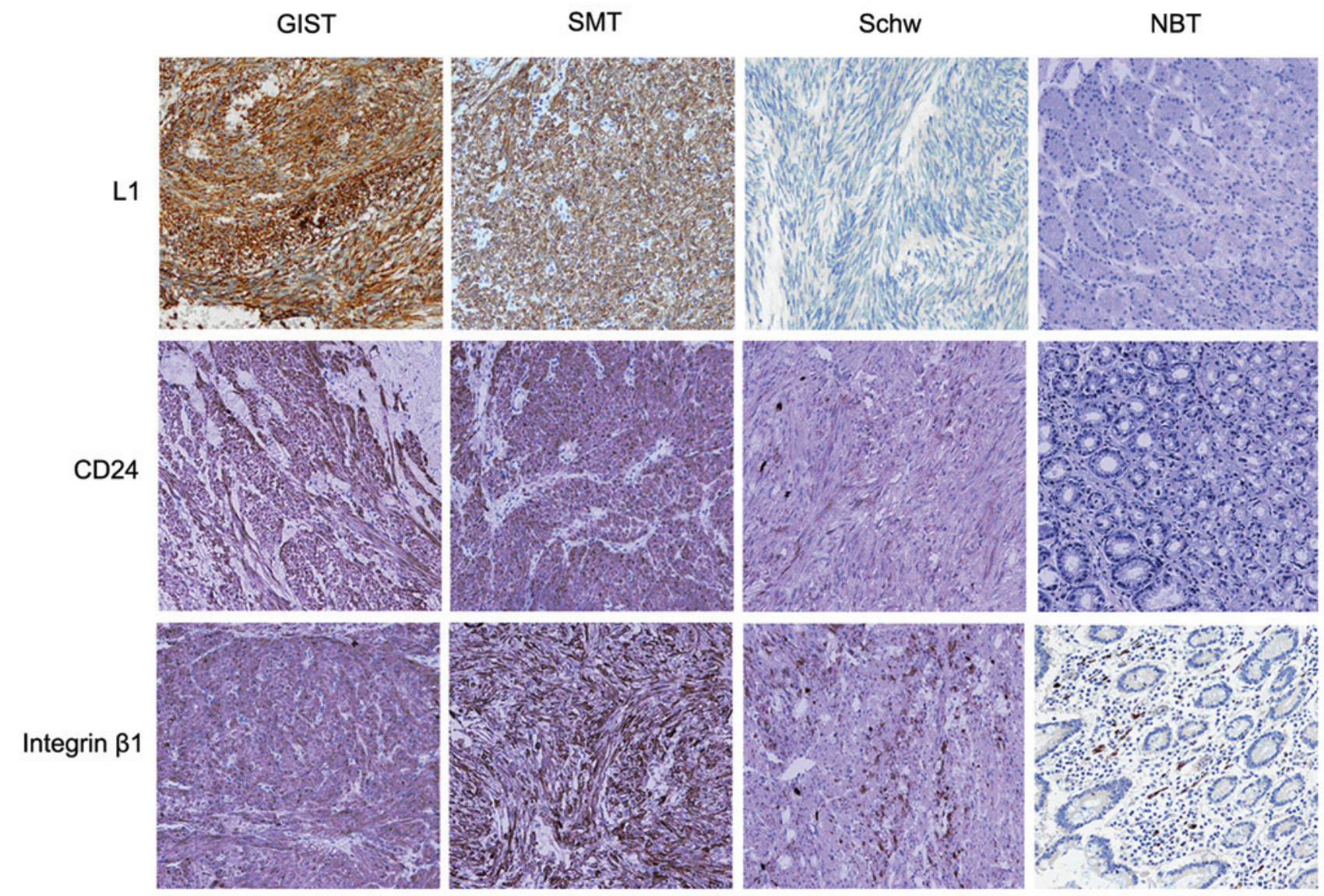

Figure 2. Expression analysis of L1, cluster of differentiation (CD)24 and integrin $\beta 1$ in gastrointestinal stromal tumors (GIST), smooth muscle tumors (SMT) and schwannomas (Schw). Sections were analyzed by immunohistochemistry. NBT, normal bowel tissue (magnification, x100).

A

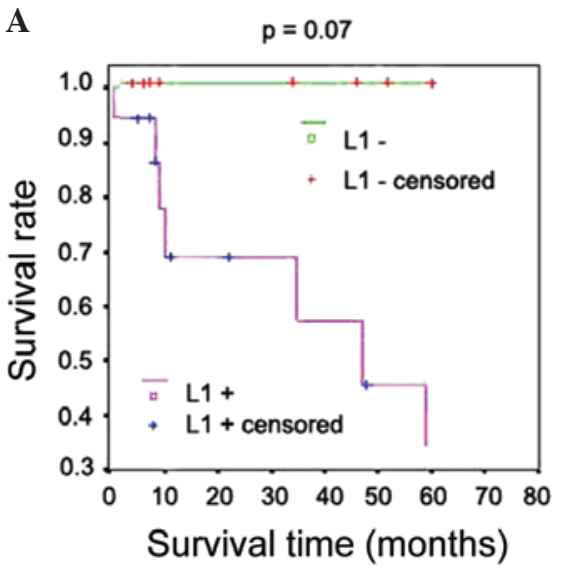

B

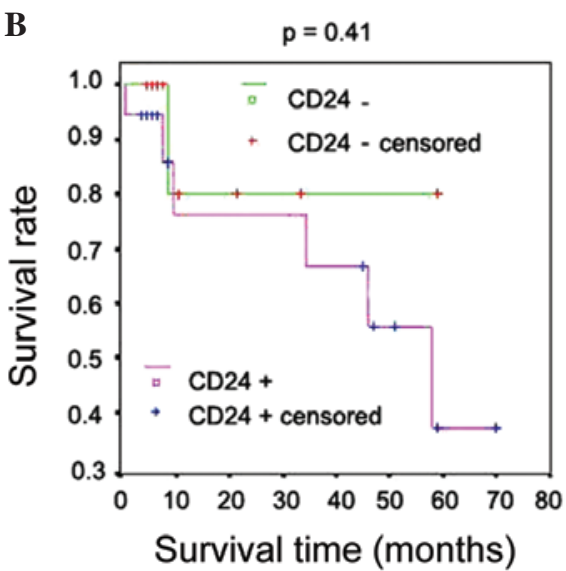

C

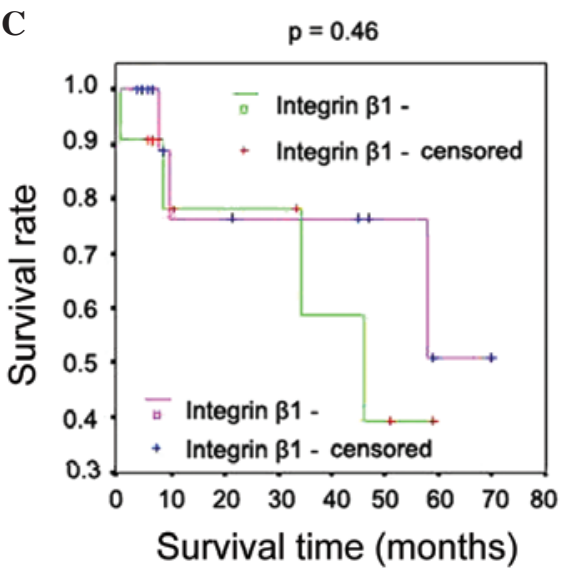

Figure 3. Kaplan-Meier survival curve analysis of gastrointestinal stromal tumor cases with expression of (A) L1, (B) cluster of differentiation (CD)24 and (C) integrin $\beta 1$. No significant correlation was identified between the expression of L1, CD24 or integrin $\beta 1$ and patient survival.

and leiomyosarcoma) or schwannoma lacked immunohistochemical staining for SMA or S-100 protein, and that no particular cell features could be observed under the electron microscope (1). Therefore, the term 'gastric stromal tumor' with a neutral tissue origin was suggested (1). Recently, a gain-of-function mutation of c-kit has been found in the majority of GISTs, which results in the ligand-independent activation of tyrosine kinase and the expression of CD117 (KIT), providing the basis for the clinical diagnosis of GISTs $(2,20)$. However, a small proportion of GIST cases with no CD117 expression remain, which introduces difficulties for the diagnosis and differential diagnosis of GISTs. The accurate evaluation of the biological behavior of GISTs is associated with the treatment and outcome of patients. The dispute has existed since the concept of GIST was proposed. Although it is well-established that all the GISTs have malignant potential, its malignant degree classification does not have a uniform standard. The tumor size and mitotic activity are typically considered as the most important criteria to differentiate between benign and malignant tumors, which 
is largely consistent with the classification standard proposed by Fletcher et al (12). However, studies have suggested that certain tumors, with a size of $<2 \mathrm{~cm}$ and without mitotic activity, may also metastasize $(21,22)$. Therefore, a search for markers of the biological behavior of GIST still has important research value for clinical application.

L1 is a transmembrane adhesion molecule originally believed to be expressed only in the nervous system, where it is involved in mediating adhesion between neurons, axonal spontaneous contraction, synapse formation, axon growth and neuronal migration (23). Expression of L1 has since been identified in various tumors of the intestine, urogenital tract, lung, rectum and kidney, and in rhabdomyosarcoma (24). High expression levels of L1 were first identified in GISTs in 2006 using immunohistochemical staining, with $73.6 \%$ (53/72) of sampled tumors expressing L1 at a high level (25). However, L1 is not expressed in fibromatosis or in gastrointestinal smooth muscle tumors.

CD24 is a highly glycosylated adhesion molecule of low molecular weight, which has been found to be expressed at high levels on the cell membrane within human hematopoietic system tumors and solid tumors, including primary liver, gastric, colorectal and breast cancers (26-28). As an adhesion molecule receptor, integrin $\beta 1$ plays a role in the developmental processes of tumors, mainly by mediating the adhesion between cells and between the cell and the ECM $(29,30)$. The present data found that L1, CD24 and integrin $\beta 1$ were expressed at a significantly higher level in GISTs than in normal control tissues. Smooth muscle tumors had barely detectable L1 expression, while there was no significant difference in L1 expression between GISTs and schwannomas. No differences in CD24 and integrin $\beta 1$ expression were identified across the three types of tumors. These results suggested that L1, CD2 4 and integrin $\beta 1$ could be useful markers in the differential diagnosis of GISTs.

L1 is an adhesion molecule with a role in regulating cell attachments and an important signaling molecule (31). CD24 is an adhesion molecule that mainly localizes to the membrane surface (32), and integrin $\beta 1$ is also an adhesion molecule receptor (33). The interaction of these three molecules has played a positive role in the migration of tumor cells (34). Fogel et al (35) found that the overexpression of L1 in melanoma promoted tumor progression and metastasis, and was closely associated with the prognosis of the patients. Gavert et al (36) determined that L1 could promote the progression and metastasis of colon cancer with the use of cell culture and animal models, and further elucidated the responsible mechanism. Firstly, L1 itself has a weak adhesion capacity, but this can be enhanced through interaction with homotypic or heterotypic molecules (37). The combination of L1 and CD24 molecules alters their conformation, facilitating the activation of endothelial cells and platelets, and enhancing the attachment of L1 with ECM ligands (38). Furthermore, the interaction of CD24 and L1 can increase the intracellular calcium concentration and strengthen signal transduction, promoting adhesion (39). Secondly, the integrin family contains multiple L1 receptors, and L1 mainly combines with integrin $\beta 1$ in the presence of $\mathrm{Mn}^{2+}$. This combination not only mediates the transfer of $\mathrm{L} 1$ into cells to reduce attachments between the tumor cells, but also induces the increased expression of adhesion molecule receptors in vascular endothelial cells and the ECM, promoting the adhesion and migration of tumor cells in these environments (40). Lastly, integrin $\beta 1$ is the receptor for $\mathrm{CD} 24$, and its interaction with $\mathrm{L} 1$ is regulated by CD24, likely through a change in the conformation of an arginineglycine-aspartate sequence following the binding of CD24 and L1 (41). The present data revealed that the expression levels of L1, CD24 and integrin $\beta 1$ were significantly correlated in the GIST cases, and that they were also associated with the expression of Ki-67. Moreover, L1 and integrin $\beta 1$ levels were significantly increased with increased invasion risk in the GISTs. However, this was not the case for CD24 expression, indicating the synergistic effects of L1, CD24 and integrin $\beta 1$ in the progression of GISTs. Therefore, the detection of L1 and integrin $\beta 1$ in combination with Ki-67 favors an accurate prediction of the biological behavior of GISTs, while elucidation of the full function of CD24 in GIST requires further investigation.

\section{Acknowledgements}

This study was supported by the China National Natural Scientific Fund (grant no. 81000901), and the Tianjin Binhai New Area Health Bureau Science and Technology Projects (grant no. 2011BHKY009).

\section{References}

1. Mazur MT and Clark HB: Gastric stromal tumors. Reappraisal of histogenesis. Am J Surg Pathol 7: 507-519, 1983.

2. Corless CL, Barnett CM and Heinrich MC: Gastrointestinal stromal tumours: origin and molecular oncology. Nat Rev Cancer 11: 865-878, 2011.

3. Hamilton SR and Aaltonen LA (eds): Mesenchymal tumours of the stomach. In: World Health Organization Classification of Tumours. Pathology and Genetics of Tumours of the Digestive System. IARC Press, Lyon, pp62-65, 2003.

4. Kiśluk J, Gryko M, Guzińska-Ustymowicz K, et al: Immunohistochemical diagnosis of gastrointestinal stromal tumors-an analysis of 80 cases from 2004 to 2010. Adv Clin Exp Med 22: 33-39, 2013.

5. Bülbül Doğusoy G; Turkish GIST Working Group Gastrointestinal stromal tumors: A multicenter study of 1160 Turkish cases. Turk J Gastroenterol 23: 203-211, 2012.

6. Montgomery E, Torbenson MS, Kaushal M, et al: Beta-catenin immunohistochemistry separates mesenteric fibromatosis from gastrointestinal stromal tumor and sclerosing mesenteritis. Am J Surg Pathol 26: 1296-1301, 2002.

7. Sugiyama T: Progress in new diagnosis and therapeutic strategy for gastrointestinal malignancy: focus on new molecular-targeted treatments. Digestion 91: 7-12, 2015.

8. Miettinen $M$ and Lasota J: Gastrointestinal stromal tumors. Gastroenterol Clin North Am 42: 399-415, 2013.

9. Patel S: Exploring novel therapeutic targets in GIST: focus on the PI3K/Akt/mTOR pathway. Curr Oncol Rep 15: 386-395, 2013.

10. Le Cesne A and Blay JY: Medical therapy of GIST; from palliative to curative treatment. Bull Acad Natl Med 196: 861-874, 2012 (In French).

11. Emile JF: Histology and molecular biology of GIST. Bull Acad Natl Med 196: 835-844, 2012 (In French).

12. Fletcher CD, Beman JJ, Corless C, et al: Diagnosis of gastrointestinal stromal tumors: A consensus approach. Hum Pathol 33: 459-465, 2002.

13. Bareck E, Ba-Ssalamah A, Brodowicz T, et al; Austrian representatives of Medical and Surgical Oncology, Pathology, Radiology, Nuclear Medicine, Gastroenterology, and Laboratory Medicine: Gastrointestinal stromal tumors: diagnosis, therapy and follow-up care in Austria. Wien Med Wochenschr 163: 137-152, 2013. 
14. Rajendra R, Pollack SM and Jones RL: Management of gastrointestinal stromal tumors. Future Oncol 9: 193-206, 2013.

15. Figge $C$, Loers G, Schachner M and Tilling T: Neurite outgrowth triggered by the cell adhesion molecule $\mathrm{L} 1$ requires activation and inactivation of the cytoskeletal protein cofilin. Mol Cell Neurosci 49: 196-204, 2012.

16. Siesser PF and Maness PF: L1 cell adhesion molecules as regulators of tumor cell invasiveness. Cell Adh Migr 3: 275-277, 2009.

17. Tischler V, Pfeifer M, Hausladen S, et al: L1CAM protein expression is associated with poor prognosis in non-small cel lung cancer. Mol Cancer 10: 127, 2011.

18. Lieberoth A, Splittstoesser F, Katagihallimath N, et al: Lewis(x) and alpha2,3-sialyl glycans and their receptors TAG-1, Contactin, and L1 mediate CD24-dependent neurite outgrowth. J Neurosci 29: 6677-6690, 2009.

19. Zhan P, Liu L, Liu B and Mao XG: Expression of integrin $\beta 1$ and its significance in squamous cell carcinoma of the cervix. Mol Med Rep 9: 2473-2478, 2014

20. Hirota S, Isozaki K, Moriyama Y, et al: Gain-of-function mutations of c-kit in human gastrointestinal stromal tumors. Science 279: 577-580, 1998.

21. Miettinen M and Lasota J: Gastrointestinal stromal tumors: pathology and prognosis at different sites. Semin Diagn Pathol 23: 70-83, 2006

22. Yi JH, Park BB, Kang JH, et al: Retrospective analysis of extra-gastrointestinal stromal tumors. World J Gastroenterol 21: 1845-1850, 2015.

23. Raveh S, Gavert N and Ben-Ze'ev A: L1 cell adhesion molecule (L1CAM) in invasive tumors. Cancer Lett 282: 137-145, 2009.

24. Zhang C, Fan Y and Fu L: Research development of L1-CAM (CD171) in human cancer. Zhonghua Bing Li Xue Za Zhi 42: 574-576, 2013 (In Chinese)

25. Kaifi JT,Strelow A,Schurr PG, et al: L1 (CD171) is highly expressed in gastrointestinal stromal tumors. Mod Pathol 19: 399-406, 2006.

26. Sagiv E and Arber N: The novel oncogene CD24 and its arising role in the carcinogenesis of the GI tract: from research to therapy. Expert Rev Gastroenterol Hepatol 2: 125-133, 2008.

27. Su MC, Hsu C, Kao HL and Jeng YM: CD24 expression is a prognostic factor in intrahepatic cholangiocarcinoma. Cancer Lett 235: 34-39, 2006.

28. Jacob J, Bellach J, Grützmann R, et al: Expression of CD24 in adenocarcinomas of the pancreas correlates with higher tumor grades. Pancreatology 4: 454-460, 2004.
29. Oh BY, Kim KH, Chung SS, et al: Role of $\beta 1$-integrin in colorectal cancer: case-control study. Ann Coloproctol 30: 61-70, 2014.

30. Chen SY, Lin JS and Yang BC: Modulation of tumor cell stiffness and migration by type IV collagen through direct activation of integrin signaling pathway. Arch Biochem Biophys 555-556: 1-8, 2014.

31. Hortsch M, Nagaraj K and Mualla R: The L1 family of cell adhesion molecules: a sickening number of mutations and protein functions. Adv Neurobiol 8: 195-229, 2014.

32. Jaggupilli A and Elkord E: Significance of CD44 and CD24 as cancer stem cell markers: an enduring ambiguity. Clin Dev Immunol 2012: 708036, 2012.

33. Jahangiri A, Aghi MK and Carbonell WS: $\beta 1$ integrin: Critical path to antiangiogenic therapy resistance and beyond. Cancer Res 74: 3-7, 2014.

34. Liakhovich AV and Aksenov NL: Topography of cell ahesion molecules CD9, CD24, L1 and N-CAM on the surface of neuroblastoma cells studied using chemical cross linking. Tsitologiia 42: 399-403, 2000.

35. Fogel M, Mechtersheimer S, Huszar M, et al: L1 adhesion molecule (CD 171) in development and progression of human malignant melanoma. Cancer Lett 189: 237-247, 2003.

36. Gavert N, Conacci-Sorrell M, Gast D, et al: L1, a novel target of $\beta$-catenin signaling, transforms cells and is expressed at the invasive front of colon cancers. J Cell Biol 168: 633-642, 2005.

37. Moulla A, Miliaras D, Sioga A, et al: The immunohistochemical expression of CD24 and CD171 adhesion molecules in borderline ovarian tumors. Pol J Pathol 64: 180-184, 2013.

38. Baumann P, Cremers N, Kroese F, et al: CD24 expression causes the acquisition of multiple cellular properties associated with tumor growth and metastasis. Cancer Res 65: 10783-10793, 2005.

39. Kleene R, Yang H, Kutsche M and Schachner M: The neural recognition molecule $\mathrm{L} 1$ is a sialic acid-binding lectin for CD24, which induces promotion and inhibition of neurite outgrowth. $\mathrm{J}$ Biol Chem 276: 21656-21663, 2001.

40. Sammar M, Aigner S and Altevogt P: Heat-stable antigen (mouse CD24) in the brain: dual but distinct interaction with P-selectin and L1. Biochim Biophys Acta 1337: 287-294, 1997.

41. Kadmon G, Imhof BA, Altevogt P and Schachner M: Adhesive hierarchy involving the cell adhesion molecules L1, CD24, and alpha 6 integrin in murine neuroblastoma N2A cells. Biochem Biophys Res Commun 214: 94-101, 1995. 